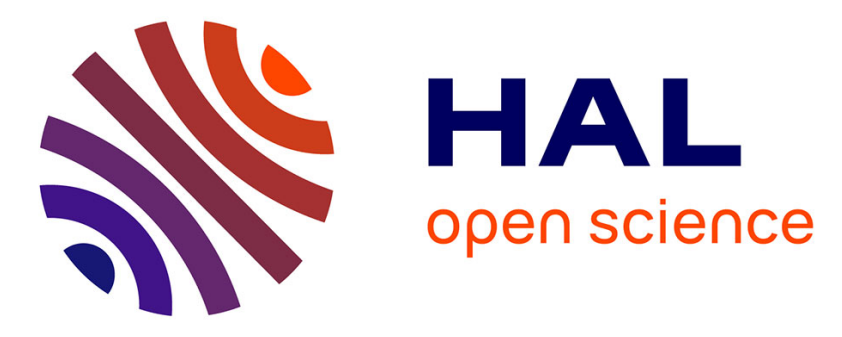

\title{
Salvage treatment in metastatic breast cancer with weekly paclitaxel and bevacizumab
}

Aris Polyzos, Kostas Kalbakis, Nikolaos Kentepozidis, Stylianos Giassas, Antonia Kalykaki, Nikolaos Vardakis, Vasiliki Bozionelou, Emmanouel Saloustros, Emmanouel Kontopodis, Vassilis Georgoulias, et al.

\section{To cite this version:}

Aris Polyzos, Kostas Kalbakis, Nikolaos Kentepozidis, Stylianos Giassas, Antonia Kalykaki, et al.. Salvage treatment in metastatic breast cancer with weekly paclitaxel and bevacizumab. Cancer Chemotherapy and Pharmacology, 2010, 68 (1), pp.217-223. 10.1007/s00280-010-1475-x . hal00629074

\section{HAL Id: hal-00629074 https://hal.science/hal-00629074}

Submitted on 5 Oct 2011

HAL is a multi-disciplinary open access archive for the deposit and dissemination of scientific research documents, whether they are published or not. The documents may come from teaching and research institutions in France or abroad, or from public or private research centers.
L'archive ouverte pluridisciplinaire HAL, est destinée au dépôt et à la diffusion de documents scientifiques de niveau recherche, publiés ou non, émanant des établissements d'enseignement et de recherche français ou étrangers, des laboratoires publics ou privés. 


\section{Salvage treatment in metastatic breast cancer with weekly paclitaxel and bevacizumab}

Aris Polyzos, Kostas Kalbakis, Nikolaos Kentepozidis, Stylianos Giassas, Antonia Kalykaki, Nikolaos Vardakis, Vasiliki Bozionelou, Emmanouel Saloustros, Emmanouel Kontopodis, Vassilis Georgoulias, Dimitris Mavroudis.

From the Hellenic Oncology Research Group (HORG), 55, Lomvardou str, 11470 Athens, Greece

Running title: paclitaxel weekly and bevacizumab in pretreated metastatic breast cancer

Keywords: paclitaxel weekly, bevacizumab, salvage chemotherapy, metastatic breast cancer

\section{Correspondence to:}

A. Polyzos, M.D., Professor, $1^{\text {st }}$ Department of Propaedeutic Medicine, Athens University School of Medicine, Laiko General Hospital, 17, Agiou Thoma str., GR 11527 Athens, Greece.

Tel.: 0030-210-7456873 and 0030-210-7456261, Fax: 0030-210-7791839, e-mail: panoraiap@med.uoa.gr 


\section{Abstract}

Background Weekly paclitaxel (P) in combination with bevacizumab (B) is an effective regimen as initial treatment of metastatic breast cancer (MBC). We investigated in a phase II study the activity of the same regimen as salvage therapy in MBC.

Methods Pretreated women with MBC received weekly $\mathrm{P}\left(90 \mathrm{mg} / \mathrm{m}^{2}\right.$ days $\left.1,8,15\right)$ and B $\left(10 \mathrm{mg} / \mathrm{m}^{2}\right.$ days 1,15$)$ every 28 days. B could continue after discontinuing $\mathrm{P}$ until disease progression. This was second-line chemotherapy for $30 \%$ and third-line or more for $70 \%$ of patients.

Results A total of 40 patients were enrolled. Median age: 61 (range 32-80) years; postmenopausal: 80\%; baseline ECOG performance status $<2$ in $80 \%$ of patients. Two patients (5\%) achieved complete response, 10 (25\%) partial response (overall response rate 30\%; 95\% CI: $15.8-44.2)$ and 10 (25\%) stable disease. The response rate was $28 \%$ for the patients who had previously received taxanes. After a median follow up of 20.6 months, the median time to progression was 4.8 months (95\% CI: 1.7-7.8), median survival 13.0 months (95\% CI 10.3-15.7) and the probability of 1 -year survival 55.5\%. Main grade 3-4 toxicities were: neutropenia 42.5\%, febrile neutropenia $5 \%$ and asthenia $10 \%$. There was one toxic death due to sepsis.

Conclusion The PB regimen is well tolerated and active as salvage therapy in pretreated women with MBC. It could be an effective option even for patients exposed to taxanes during prior treatments. 


\section{Introduction}

Metastatic breast cancer (MBC) remains an incurable disease and although several advances in its management have been made in recent years, there is no significant prolongation of survival and the treatment remains palliative [1]. Combination chemotherapy used as first-line treatment in advanced disease usually achieves objective responses in $35-75 \%$ of patients. Subsequent lines of chemotherapy yield much lower response rates followed by short survival [2]. Therefore, further therapeutic advances require strategies based on an understanding of breast cancer biology, such as invasion, metastasis and tumor angiogenesis. Laboratory and clinical evidence support a significant role of angiogenesis in breast cancer development and progression $[3,4]$.

Vascular endothelial growth factor (VEGF) is among the most potent stimulators of angiogenesis. VEGF stimulates endothelial proliferation and cell migration, inhibits endothelial apoptosis, increases vascular permeability, induces proteinases that remodel the extracellular matrix and inhibits antigen-presenting dendritic cells. The role of VEGF in healthy adults is limited in wound healing and in female reproductive cycle and, therefore, VEGF is a suitable therapeutic target in cancer treatment $[5,6]$. Bevacizumab (Avastin ${ }^{\circledR}$ Hoffmann-La Roche Ltd) is a recombinant humanized monoclonal antibody against all major isoforms of human VEGF. Preclinical data suggest that bevacizumab (B) inhibits the formation of new vessels, induces the regression of existing abnormal tumor vasculature leading to a normalization of the remaining tumor vasculature and to a better penetration of chemotherapeutic agents into the cancer cells $[7,8]$. As a single agent in a phase I-II study in 75 patients with previously treated $\mathrm{MBC}, \mathrm{B}$ achieved a 9.3\% objective response rate with minimal toxicities [9]. In a phase III trial in patients previously 
treated with anthracyclines and taxanes, the combination of capecitabine plus B significantly increased the response rate, but not the progression free survival (PFS) nor the overall survival (OS) [10]. More recently, in another phase III trial the combination of B plus paclitaxel (P) administered weekly as first-line treatment also increased the response rate ( $36.9 \%$ vs $21.2 \%$ ) compared to single agent paclitaxel, had a favorable effect on PFS (11.8 vs 5.9 months), but did not change OS [11]. The regimen was very well tolerated with a remarkably low incidence of febrile neutropenia ( $<1 \%$ overall). In a recently presented meta-analysis of three randomized trials in patients with $\mathrm{MBC}$ evaluating $\mathrm{B}$ plus first-line chemotherapy regimens (taxane-, anthracycline-, or capecitabine-based), median PFS improved from 6.7 to 9.2 months $(\mathrm{p}<0.0001)$ in the B arms; however, OS showed no statistically significant difference between the arms $(\mathrm{p}=0.56)$ [12].

In the present phase II study, we aimed to evaluate the efficacy and safety of the same $\mathrm{P}$ weekly plus $\mathrm{B}$ combination as a salvage regimen in heavily pretreated patients with MBC. The weekly schedule of $\mathrm{P}$ was chosen because of its superiority over the every 3 -weeks $\mathrm{P}$ in terms of efficacy and its milder toxicity $[13,14]$.

\section{Patients and methods}

\section{Patient Selection}

Women with histologically confirmed and bi-dimensionally measurable metastatic adenocarcinoma of the breast, who had received at least on line of chemotherapy for metastatic disease, were enrolled. Prior hormonal therapy was allowed provided that it had been discontinued at least 4 weeks before entry into the study. Prior radiotherapy was allowed if the measurable lesions were outside the radiation fields. Patients should have had a performance status (WHO) of $0-2$, a life expectancy of at 
least 3 months and adequate organ function, including an absolute neutrophil count $\geq$ $1,500 / \mu 1$, platelet count $\geq 100,000 / \mu \mathrm{l}$, total bilirubin level $\leq 1.5 \mathrm{mg} / \mathrm{dl}$, AST less than or equal to three times the upper limit of normal, and a serum creatinine concentration $\leq 2.0 \mathrm{mg} / \mathrm{dl}$. Other factors that rendered the patient ineligible included the presence of an active uncontrolled infection, uncontrolled diabetes mellitus, uncontrolled hypertension, untreated or symptomatic brain metastases, a history of a second malignancy in the previous 5 years other than resected basal cell and/or squamous cell carcinoma of the skin or in situ cervical carcinoma. Patients were excluded if they were currently taking therapeutic anticoagulant agents or more than $325 \mathrm{mg}$ of aspirin daily. Patients with any chronic toxicity including peripheral neuropathy $>$ grade 2 NCI CTC were also excluded. The protocol was approved by the Scientific and Ethics Committees of the participating institutions of the Hellenic Oncology Research Group. All patients signed an informed consent prior to their entry into the study.

\section{Treatment}

All patients received paclitaxel (P) $90 \mathrm{mg} / \mathrm{m}^{2}$ iv on days 1,8 and 15 and bevacizumab (B) $10 \mathrm{mg} / \mathrm{m}^{2}$ iv on days 1 and 15 in cycles every 28 days. Antihypertensive treatment was given at the discretion of the treating physician if needed. The prophylactic use of granulocyte colony-stimulating factor (G-CSF) was not routinely allowed, but physicians were free for using G-CSF in case of severe neutropenia or febrile neutropenia. In case of a continuing objective response, treatment was allowed to be continued until best response was achieved or significant toxicity developed. Patients with stable disease as their best response were scheduled to receive up to 6 cycles of treatment. In both groups of patients, B could continue after discontinuing $\mathrm{P}$ until disease progression. Patients with progressive disease at any time during the treatment 
or experiencing unacceptable toxicity as well as patients withdrawing their consent were immediately taken off study. Evaluable for toxicity were all patients who received at least one cycle of treatment. All toxicities were graded according to the National Cancer Institute common toxicity criteria [15]. Dose modifications for hematological and non-hematological toxicities were as follows: for febrile neutropenia, grade IV neutropenia or grade III-IV thrombocytopenia, the dose of $\mathrm{P}$ was reduced by $20 \%$. Also in cases of grade $\geq 2$ asthenia or neurotoxicity, a $25 \%$ reduction of the $\mathrm{P}$ dose was performed. In case of severe hypertension or proteinuria B dose was reduced by $50 \%$.

\section{Response Evaluation}

All patients had tumor measurements (by physical examination, CT or MRI) performed within 4 weeks of study registration and subsequently after each two cycles of treatment. Hematological toxicity was monitored with weekly blood counts, except in cases of grade IV or febrile neutropenia where daily monitoring was performed. Standard evaluation by history, physical examination and routine laboratory tests was performed before each treatment. Imaging studies with ultrasound or computed tomography scans were performed after every 2 cycles. Evaluable for response were all patients who completed at least 2 cycles of treatment and had reassessment of their measurable disease. Complete response (CR), partial response (PR), stable disease (SD) and progressive disease (PD) were scored using the standard RECIST criteria [16]. Radiological responses were confirmed by an independent panel of radiologists. CR and PR had to be maintained for a minimum of 4 weeks. The duration of response was measured from the first documentation of response to disease progression. Time to progression was determined by the interval between the initiation of therapy to the 
first date that disease progression was objectively documented. Overall survival was measured from the date of study entry to the date of death. The follow-up time was measured from the first day of treatment administration to the last contact or death.

\section{Statistical Methods}

The primary end point of this phase II study was the efficacy of the two drug chemotherapy regimen in terms of objective response rate (complete+partial response); secondary end points were the evaluation of toxicity, time to progression and overall survival. According to Simon's two-stage optimal design [17], assuming that the expected overall response rate will be at least $30 \%$ and the minimum acceptable response rate $14 \%$, a sample of 25 patients will be required in the first step. If a minimum of 4 responses is observed a total of 40 patients will be accrued. Thereby, if at least 10 responses occur the treatment will be declared sufficiently promising. The probability of accepting a treatment with a real response rate of less than or equal to $14 \%$ will be $5 \%$. On the other hand, the risk of rejecting a treatment (at the second stage) with a response rate of at least $30 \%$ will be $20 \%$.

All patients who received at least one cycle of chemotherapy were included in the toxicity analysis. The survival distributions for response duration, TTP and overall survival were estimated using the Kaplan-Meier method [18]. Data analysis was performed using SPSS 11.0 (SPSS, Inc., Chicago, IL).

\section{Results}

Between June 2007 and July 2009, 40 patients with measurable MBC were enrolled in this multicenter phase II study. All patients were evaluable for toxicity and 39 for 
response to the treatment. The reason why one patient was not evaluable for response was patient's withdrawal from study.

\section{Patient Characteristics}

These are shown in Table 1. The median age of the patients was 61 years, $80 \%$ had a performance status of $0-1$, and $80 \%$ were postmenopausal. Thirty-one (77.5\%) patients had hormone receptor-positive tumors and none had HER2 overexpression (3+ by immunohistochemistry or FISH positive). Twenty (50\%) patients had previously received chemotherapy as adjuvant or neo-adjuvant treatment. This was anthracycline-based in $16(40 \%)$ patients and non-anthracycline-containing in 3 (7.5\%). All patients had received chemotherapy for advanced disease: $26(65 \%)$ had received docetaxel, $3(7.5 \%)$ both docetaxel and paclitaxel and $30(75 \%)$ patients anthracyclines. The median number of prior lines of therapy was two (range 1-6). There were seventeen $(42.5 \%)$ patients with more than 3 prior lines of therapy. Twenty-eight (70\%) patients had visceral disease including 18 (45\%) with lung and $19(48 \%)$ with liver metastases. Nineteen (48\%) patients also had bone involvement.

\section{Treatment Administration}

A total of 171 cycles of $\mathrm{P}$ and $\mathrm{B}$ were administered on an outpatient basis. The median number of cycles per patient was 4 (range 1-11). The median cycle duration per patient was 28 days (range 28-38). The treatment had to be delayed in 33 of 171 (19.3\%) cycles for the following reasons: hematological toxicity $(n=5)$, nonhematological $(n=1)$ and the rest were all due to other reasons unrelated to toxicity, for example, pending imaging studies for response assessment or late admissions due 
to patients' personal reasons. Dose reduction was performed in 57 of 171 (33.3\%) cycles for hematological $(n=18)$, non-hematological toxicity $(n=17)$, both $(n=1)$, and other reasons $(n=21)$. Due to the lack of severe toxicity $50 \%$ of the patients tolerated the full planned doses of the two drugs in all cycles. The median dose intensity for $\mathrm{P}$ was 48.4 (range, 17.4-67.5) $\mathrm{mg} / \mathrm{m}^{2} /$ week which represents $72 \%$ (range $25.8 \%-100 \%$ ) of the planned dose. Similarly, for B the median dose intensity was 4.0 (range, 1.45.0) $\mathrm{mg} / \mathrm{Kg} /$ week which represents $80 \%$ (range, $28.0 \%-100 \%$ ) of the planned dose.

\section{Treatment Efficacy}

In an intention-to-treatment analysis, there were 2 CRs (5\%) and 10 PRs (25\%) for an overall response rate of $30 \%$ (95\% CI $15.8-44.2 \%$ ). Additionally, 10 patients (25\%) had stable disease and $18(45 \%)$ progressive disease. The response rate was $28 \%$ (9 out of 32) for the patients who had previously received taxanes. Response rates were $31.6 \%$ for liver, $33.3 \%$ for lung, $25 \%$ for lymph nodes and $50 \%$ for local disease. The median duration of response was 7.6 months (range 3.2-19.8) and the median time to tumor progression was 4.8 months (range 0.5-26.1). After a median follow-up time of 20.3 months (range 0.5-31.9 months), 26 (65\%) patients had died, all but one due to disease progression. The median survival time was estimated to be 13.0 months (min$\max$ 0.5-31.9) months. The Kaplan-Meier estimated probability of 1-year survival for the entire group was $55.5 \%$.

\section{Treatment Toxicity}

Hematological toxicity, which is shown in Table 2, included $4(10.0 \%)$ patients with grade IV, and $13(32.5 \%)$ patients with grade III neutropenia. In addition, 1 (2.5\%) patient had grade III thrombocytopenia, and 8 (20\%) patients developed grade II 
anemia. In two patients (5\%) grade III and IV neutropenia was associated with fever and required hospitalization and treatment with intravenous antibiotics. There was one treatment-related death due to grade IV febrile neutropenia with sepsis. This was a patient with extensive liver and bone metastases who received the study regimen as second-line therapy and eight days after the first cycle developed neutropenic fever with diarrhea and abdominal pain and died despite aggressive supportive measures.

Non-hematological toxicity was generally mild to moderate and transient (Table 2). The most common non-hematologic toxicity was asthenia that was grade III in 4 (10\%) and grade II in $13(32 \%)$ patients. One (2.5\%) and three (7.5\%) patients developed grade IV and III diarrhea while one $(2.5 \%)$ and $4(10 \%)$ grade III and II neurotoxicity, respectively. For the treatment of severe neutropenia rhG-CSF was administered to $16(40 \%)$ patients.

\section{Discussion}

With the introduction of taxanes in the adjuvant and neo-adjuvant setting of breast cancer, most patients with advanced disease have already been exposed to the most potent agents: the anthracyclines and the taxanes. Therefore, for the treatment of patients who relapse with hormone receptors negative and HER2 negative tumors the only alternative treatment remains chemotherapy in a second and third-line setting. Paclitaxel (P) has demonstrated single agent response rates of $35 \%$ to $53 \%$ even as second or third-line treatment [19]. In addition, bevacizumab (B) combined with several chemotherapeutic agents has shown a synergistic effect that was translated into an increase of the response rate in pretreated patients [10] and an increase of the response rate and progression free survival (PFS) as first-line treatment [11] in MBC. Other studies in chemotherapy-naive patients such as the AVADO where B was 
combined with docetaxel demonstrated a better PFS and response rate (RR) compared with chemotherapy alone with similar quality of life [20-22]. More recently, in the RIBBON I study the addition of B to capecitabine or taxane or anthracycline-based regimens in first-line treatment resulted in a significant improvement in RR and PFS [23]. In a most recent phase II study of the North Central Cancer Treatment Group (NCCTG) N0432 B was combined with docetaxel and capecitabine as first-line treatment in advanced disease. It is important that during adjuvant or neo-adjuvant treatment $38 \%$ of patients had been exposed to anthracyclines and $40 \%$ to taxanes. An observed overall RR of $49 \%$ with median OS and PFS of 28.4 and 11.1 months, respectively, were reported [24].

In the present phase II study, P weekly and B biweekly were administered in pretreated patients with MBC $70 \%$ of whom had visceral metastases. A $30 \%$ overall RR was documented while an additional $25 \%$ of patients demonstrated stable disease. The response rate for patients who had previously received taxanes was $28 \%$. Responses were seen in all sites including liver (31.6\%), lung (33.3\%) and lymph nodes $(25.0 \%)$. The median duration of response (7.6 months), time to progression (4.8 months) and estimated survival (13.0 months) are not very different from the results reported with chemotherapy alone [19]. Similar results have also been reported by other investigators applying the same agents in a salvage regimen with some differences in regards to the intervals of paclitaxel administration (biweekly) and patient's characteristics since one third of them were HER2 positive [25]. The toxicity of the PB regimen in the present study was not severe, and with the exception of one patient with neutropenic sepsis that died, the rest of the patients recovered uneventfully from neutropenia treated with GCSF and oral antibiotics on an outpatient basis. In the other studies applying B and chemotherapy, significant neutropenia and 
vascular side effects have been reported. In the NCCTG study, although B plus docetaxel plus capecitabine was administered as first-line regimen, the side effects were more severe with $18 \%$ of patients demonstrating neutropenia and $18 \%$ grade $3-4$ diarrhea [24]. Interestingly, hypertension was not a significant problem in our study group. In several other studies, some patients suffered from cerebrovascular ischemia possibly related to treatment $[10,11,23-25]$.

The role of B in advanced breast cancer administered together with first-line treatment is being evaluated. The reported results from three large randomized studies $[11,20,23]$ combining B with chemotherapy showed improvement in PFS but not OS, and this was also confirmed in a recently presented pooled analysis of these three studies [12] and has led to a more critical re-evaluation of the added therapeutic value of $\mathrm{B}$ in MBC. The role of B in pre-treated metastatic disease has been evaluated in a few studies $[10,25,26]$ with no effect on overall survival. In the RIBBON-2 study, which evaluated the combination of $\mathrm{B}$ with various chemotherapies (taxane, gemcitabine, capecitabine, or vinorelbine) to treat $\mathrm{MBC}$ in the second line, the addition of B improved PFS of HER2-negative MBC patients with differing clinical characteristics and disease histories [26]. Therefore the results of the present study contribute to the growing body of evidence that combinations of B and chemotherapy in pre-treated $\mathrm{MBC}$ are active regimens which may offer significant disease control and palliation. Other studies in pretreated patients have evaluated the addition of B to metronomic chemotherapy, since such combinations maybe more effective and well tolerated $[27,28]$.

An increasingly important issue is the cost-effectiveness of B administration in MBC. In the only economic analysis published recently, it was reported that the addition of B to paclitaxel therapy is expensive considering the clinical benefit gained 
in terms of quality-adjusted life-years [29]. The lack of a significant survival benefit combined with the increased cost of treatment make the evaluation of predictive biomarkers for B's efficacy an important priority [30]. Until such biomarkers become available and prospective studies in selected patients show significant survival benefit, the usage of B in MBC will continue to be a matter of controversy.

In conclusion, current evidence suggests that the addition of $\mathrm{B}$ to initial chemotherapy may improve clinical outcome but not survival of patients with MBC. The role of $\mathrm{B}$ in the treatment of patients with resistant disease seems to be less important. Although this is a small study compared with RIBBON-2, our results show that paclitaxel weekly and B is an active and well-tolerated regimen in pre-treated MBC. The relative value of adding B to standard chemotherapy in the second or subsequent line setting will have to be weighed against the high cost of therapy and the lack of survival benefit.

\section{Disclosures}

None 
Table 1 Patient characteristics

\begin{tabular}{|c|c|}
\hline Number of patients & 40 \\
\hline \multicolumn{2}{|l|}{ Age } \\
\hline Median & 61 \\
\hline Range & $32-84$ \\
\hline \multicolumn{2}{|l|}{ Performance status (WHO) } \\
\hline 0 & $12(30 \%)$ \\
\hline 1 & $20(50 \%)$ \\
\hline 2 & $8(20 \%)$ \\
\hline \multicolumn{2}{|l|}{ Menopausal status } \\
\hline Premenopausal & $8(20 \%)$ \\
\hline Postmenopausal & $32(80 \%)$ \\
\hline \multicolumn{2}{|l|}{ Histological type } \\
\hline Ductal & $29(73 \%)$ \\
\hline Lobular & $7(17 \%)$ \\
\hline Mixed & $4(10 \%)$ \\
\hline \multicolumn{2}{|l|}{ Hormonal receptor status } \\
\hline $\mathrm{ER}+\mathrm{PR}+$ & $18(46 \%)$ \\
\hline $\mathrm{ER}+\mathrm{PR}-$ & $9(22 \%)$ \\
\hline ER-PR+ & $4(10 \%)$ \\
\hline ER-PR- & $9(22 \%)$ \\
\hline \multicolumn{2}{|l|}{ Prior treatment } \\
\hline Surgery & $33(82,5 \%)$ \\
\hline Adjuvant and/or neoadjuvant chemotherapy & $20(50 \%)$ \\
\hline Chemotherapy for advanced disease & $40(100 \%)$ \\
\hline Radiotherapy for adjuvant and/or metastatic disease & $26(65 \%)$ \\
\hline \multicolumn{2}{|l|}{ Adjuvant + Neoadjuvant Chemo $(\mathrm{n}=20)$} \\
\hline Anthracycline + Taxane & $8(40 \%)$ \\
\hline Anthracycline only & $10(50 \%)$ \\
\hline Taxane only & $1(5) \%$ \\
\hline Other & $1(5 \%)$ \\
\hline \multicolumn{2}{|l|}{ Metastatic chemo $\quad(n=40)$} \\
\hline Docetaxel & $26(65.0 \%)$ \\
\hline Docetacel and Paclitaxel & $3(7.5 \%)$ \\
\hline Anthracycline & $30(75 \%)$ \\
\hline Other & $7(17.5 \%)$ \\
\hline \multicolumn{2}{|l|}{ Line of therapy } \\
\hline $2^{\text {nd }}$ line & $12(30 \%)$ \\
\hline$\geq 3^{\text {rd }}$ line & $28(70 \%)$ \\
\hline \multicolumn{2}{|l|}{ Measurable disease sites } \\
\hline Local & $4(10 \%)$ \\
\hline Lymph nodes & $24(60 \%)$ \\
\hline Lung & $18(45 \%)$ \\
\hline Liver & $19(48 \%)$ \\
\hline Pleura & $14(35 \%)$ \\
\hline Brain & $3(7 \%)$ \\
\hline Bones & $19(50 \%)$ \\
\hline Skin & $2(5 \%)$ \\
\hline \multicolumn{2}{|l|}{ Number of disease sites per patient } \\
\hline 1 & $15(38 \%)$ \\
\hline 2 & $9(22 \%)$ \\
\hline$\geq 3$ & $16(41 \%)$ \\
\hline
\end{tabular}


Table 2 Worst toxicity in all cycles

\begin{tabular}{|c|c|c|c|c|}
\hline \multirow[b]{2}{*}{ Toxicity } & \multicolumn{4}{|c|}{ Number of patients (\%), NCI grade } \\
\hline & I & II & III & IV \\
\hline Neutropenia & $9(22.5)$ & $3(7.5)$ & $13(32.5)$ & $4(10.0)$ \\
\hline Anemia & $23(57.5)$ & $8(20.0)$ & - & - \\
\hline Thrombocytopenia & $6(15.0)$ & $2(5.0)$ & $1(2.5)$ & - \\
\hline Febrile neutropenia & - & - & $1(2.5)$ & $1(2.5)$ \\
\hline Nausea & $8(20.0)$ & $2(5.0)$ & $1(2.5)$ & - \\
\hline Vomiting & $2(5.0)$ & $2(5.0)$ & $1(2.5)$ & - \\
\hline Diarrhea & $4(10.0)$ & $4(10.0)$ & $3(7.5)$ & $1(2.5)$ \\
\hline Stomatitis & $2(5.0)$ & $3(7.5)$ & - & - \\
\hline Constipation & $6(15.0)$ & $2(5.0)$ & - & - \\
\hline Neurotoxicity & $9(22.5)$ & $4(10.0)$ & $1(2.5)$ & - \\
\hline Allergic reactions & $3(7.5)$ & - & $2(5.0)$ & - \\
\hline Skin toxicity & $3(7.5)$ & $1(2.5)$ & - & - \\
\hline Asthenia & $11(27.5)$ & $13(32.5)$ & $4(10.0)$ & - \\
\hline Edema & $2(5.0)$ & - & - & - \\
\hline Fever & $6(15.0)$ & - & - & - \\
\hline Nail disorder & - & $3(7.5)$ & - & - \\
\hline Bleeding & $8(20.0)$ & & - & - \\
\hline Hypertension & $1(2.5)$ & $1(2.5)$ & - & - \\
\hline Headache & $4(10.0)$ & $2(5.0)$ & & \\
\hline
\end{tabular}




\section{References}

[1] Fossati R, Confalonieri C, Torri V, Ghislandi E, Penna A, Pistotti V, Tinazzi A, Liberati A (1998) Cytotoxic and hormonal treatment for metastatic breast cancer: a systematic review of published randomized trials involving 31,510 women. J Clin Oncol 16: 3439-3460.

[2] Vogel CL, Azevedo S, Hilsenbeck S, East DR, Ayub J (1992) Survival after first recurrence of breast cancer. The Miami experience. Cancer 70: 129-135.

[3] Folkman J (1990) What is the evidence that tumors are angiogenesis dependent? J Natl Cancer Inst. 82: 4-6.

[4] Gasparini G (1999) Angiogenesis in breast cancer: role in biology, tumor progression, and prognosis. In: Bowcock A Ed, Breast cancer: molecular genetics, pathogenesis, and therapeutics. Torowa, NJ, Humana Press. pp 341 371.

[5] Ferrara N, Gerber HP, LeCouter J (2003) The biology of VEGF and its receptors. Nat Med 9: 669-676.

[6] Relf M, LeJeune S, Scott PA, Fox S, Smith K, Leek R, Moghaddam A, Whitehouse R, Bicknell R, Harris AL (1997) Expression of the angiogenic factors vascular endothelial cell growth factor, acidic and basic fibroblast growth factor, tumor growth factor beta-1, platelet-derived endothelial cell growth factor, placenta growth factor, and pleiotrophin in human primary breast cancer and its relation to angiogenesis. Cancer Res 57: 963-969.

[7] Jain RK (2005) Normalization of tumor vasculature: an emerging concept in antiangiogenic therapy. Science 307: 58-62.

[8] Drevs J (2008) VEGF and angiogenesis: implications for breast cancer therapy. Eur J Cancer 6: 7-13.

[9] Cobleigh M, Miller K, Langmuir V (2001) Phase II dose escalation trial of Avastin (bevacizumab) in women with previously treated metastatic breast cancer. Breast Cancer Res Treat 69: 301.

[10] Miller KD, Chap LI, Holmes FA, Cobleigh MA, Marcom PK, Fehrenbacher L, Dickler M, Overmoyer BA, Reimann JD, Sing AP, Langmuir V, Rugo HS (2005) Randomized phase III trial of capecitabine compared with bevacizumab plus capecitabine in patients with previously treated metastatic breast cancer. J Clin Oncol 23: 792-799. 
[11] Miller K, Wang M, Gralow J, Dickler M, Cobleigh M, Perez EA, Shenkier T, Cella D, Davidson NE (2007) Paclitaxel plus bevacizumab versus paclitaxel alone for metastatic breast cancer. N Engl J Med 357: 2666-2676.

[12] O'Shaughnessy J, Miles D, Gray RJ, Dieras V, Perez EA, Zon R, Cortes J, Zhou X, Phan S, Miller K (2010) A meta-analysis of overall survival data from three randomized trials of bevacizumab (BV) and first-line chemotherapy as treatment for patients with metastatic breast cancer (MBC). J Clin Oncol 28:15s (abstr 1005)

[13] Green MC, Buzdar AU, Smith T, Ibrahim NK, Valero V, Rosales MF, Cristofanilli M, Booser DJ, Pusztai L, Rivera E, Theriault RL, Carter C, Frye D, Hunt KK, Symmans WF, Strom EA, Sahin AA, Sikov W, Hortobagyi GN (2005) Weekly paclitaxel improves pathologic complete remission in operable breast cancer when compared with paclitaxel once every 3 weeks. J Clin Oncol 23: 5983-5992.

[14] Seidman AD, Berry D, Cirrincione C, Harris L, Muss H, Marcom PK, Gipson G, Burstein H, Lake D, Shapiro CL, Ungaro P, Norton L, Winer E, Hudis C (2008) Randomized phase III trial of weekly compared with every-3-weeks paclitaxel for metastatic breast cancer, with trastuzumab for all HER-2 overexpressors and random assignment to trastuzumab or not in HER-2 nonoverexpressors: final results of Cancer and Leukemia Group B protocol 9840. J Clin Oncol 26: 1642-1649.

[15] National Cancer Institute. (2003). Common Toxicity Criteria Vs 3.0.

[16] Therasse P, Arbuck SG, Eisenhauer EA, Wanders J, Kaplan RS, Rubinstein L, Verweij J, Van GM, van Oosterom AT, Christian MC, Gwyther SG (2000) New guidelines to evaluate the response to treatment in solid tumors. European Organization for Research and Treatment of Cancer, National Cancer Institute of the United States, National Cancer Institute of Canada. JNCI Cancer Spectrum 92: 205-216.

[17] Simon R. (1989). Optimal two-stage designs for phase II clinical trials. Control Clin.Trials 10: 1-10.

[18] Kaplan EL, Meier P (1959) Nonparametric estimation from incomplete observations. J Am Stat Assoc 53: 457-481.

[19] Seidman AD, Reichman BS, Crown JP, Yao TJ, Currie V, Hakes TB, Hudis CA, Gilewski TA, Baselga J, Forsythe P (1995) Paclitaxel as second and 
subsequent therapy for metastatic breast cancer: activity independent of prior anthracycline response. J Clin Oncol 13: 1152-1159.

[20] Miles DW, Chan A, Dirix LY, Cortés J, Pivot X,Tomczak P, Delozier T, Sohn JH,Provencher L, Puglisi F, Harbeck N, Steger GG, Schneeweiss A, Wardley AM, Chlistalla A, Romieu G (2010) Phase III study of bevacizumab plus docetaxel compared with placebo plus docetaxel for the first-line treatment of human epidermal growth factor receptor 2-negative metastatic breast cancer. J Clin Oncol 28: 3239-3247.

[21] Greil R, Im Y, Pienkowski T, Waderly A, Awada A, Ciruelos E, Freitas-Junor R, Fumoleau P, Snuranpong V, Miles DW (2009) Quality of life among patients with locally recurrent or metastatic breast cancer: results from the phase III AVADO study of first-line bevacizumab plus docetaxel versus docetaxel plus placebo. EJC Supplements 7: 266-266.

[22] Pivot X, Verma S, Thomssen C, Passos-Coelho JL, Latini L, Ciruelos E, Silva M, von Moos R, Chang H, Miles DW (2009) Clinical benefit of bevacizumab (BV) plus first-line docetaxel (D) in elderly patients (pts) with locally recurrent (LR) or metastatic breast cancer (mBC): AVADO study. J Clin Oncol, ASCO Annual Meeting Proceedings 27(5S): 1094.

[23] Robert NJ, Dieras V, Glaspy JA, Brufsky A, Bondareknko I, Lipatov O, Perez E, Yaderly D, Xhou X, Phan S (2009) RIBBON-1: Randomized, double-blind, placebo-controlled, phase III trial of chemotherapy with or without bevacizumab (B) for first-line treatment of HER2-negative locally recurrent or metastatic breast cancer (MBC). J Clin Oncol, ASCO Annual Meeting. Proceedings 27(15S): 1005.

[24] Perez EA, Hillman DW, Dentchev T, Le-Lindqwister NA, Geeraerts LH, Fitch TR, Liu H, Graham DL, Kahanic SP, Gross HM, Patel TA, Palmieri FM, Dueck AC (2010) North Central Cancer Treatment Group (NCCTG) N0432: phase II trial of docetaxel with capecitabine and bevacizumab as first-line chemotherapy for patients with metastatic breast cancer. Ann Oncol 21: 269274.

[25] Ardavanis A, Doufexis D, Kountourakis P, Malliou S, Karagiannis A, Kardara E, Sykoutri D, Charalampia M, Rigatos G (2009) Salvage therapy of pretreated advanced breast cancer with bevacizumab and paclitaxel every two weeks: a retrospective case review study. BMC.Cancer 9: 338. 
[26] Brufsky A, Rivera RR, Hurvitz SA, Bondarenko IN, Smirnov V, Valero V, Rugo HS, Swamy R, Mu H, Perez EA (2010) Progression-free survival (PFS) in patient subgroups in RIBBON-2, a phase III trial of chemotherapy (chemo) plus or minus bevacizumab (BV) for second-line treatment of HER2-negative, locally recurrent or metastatic breast cancer (MBC). J Clin Oncol 28:15s (abstr 1021).

[27] Dellapasqua S, Bertolini F, Bagnardi V, Campagnoli E, Scarano E, Torrisi R, Shaked Y, Mancuso P, Goldhirsch A, Rocca A, Pietri E, Colleoni M (2008) Metronomic cyclophosphamide and capecitabine combined with bevacizumab in advanced breast cancer. J Clin Oncol 26: 4899-4905.

[28] Garcia-Saenz JA, Martin M, Calles A, Bueno C, Rodriguez L, Bobokova J, Custodio A, Casado A, Diaz-Rubio E (2008) Bevacizumab in combination with metronomic chemotherapy in patients with anthracycline- and taxanerefractory breast cancer. J Chemother 20: 632-639.

[29] Dedes KJ, Matter-Walstra K, Schwenkglenks M, Pestalozzi BC, Fink D, Brauchli P, Szucs TD (2009) Bevacizumab in combination with paclitaxel for HER-2 negative metastatic breast cancer: an economic evaluation. Eur J Cancer 45: 1397-1406.

[30] Schneider BP, Wang M, Radovich M, Sledge GW, Badve S, Thor A, Flockhart DA, Hancock B, Davidson N, Gralow J, Dickler M, Perez EA, Cobleigh M, Shenkier T, Edgerton S, Miller KD (2008) Association of vascular endothelial growth factor and vascular endothelial growth factor receptor-2 genetic polymorphisms with outcome in a trial of paclitaxel compared with paclitaxel plus bevacizumab in advanced breast cancer: ECOG 2100. J Clin Oncol 26: 4672-4678. 